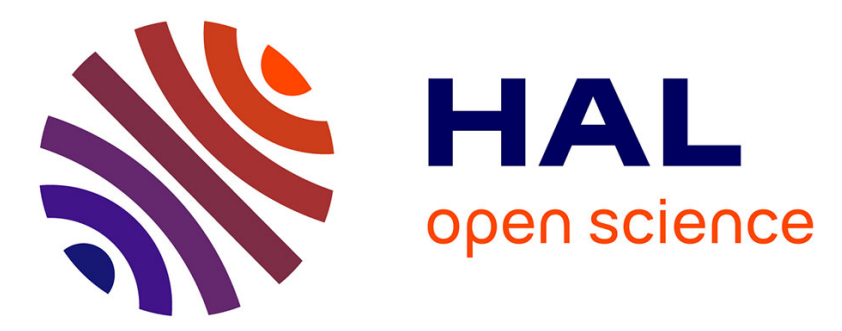

\title{
A fuzzy approach for discrete event systems recovery.
} Eugénia Minca, Daniel Racoceanu, Florin Dragomir, Noureddine Zerhouni

\section{To cite this version:}

Eugénia Minca, Daniel Racoceanu, Florin Dragomir, Noureddine Zerhouni. A fuzzy approach for discrete event systems recovery.. IFAC - International Federation of Automatic Control. 4th IFAC Conference on Management and Control of Production and Logistics, MCPL'2007., Sep 2007, Sibiu, Romania. pp.585-590. hal-00189140

\section{HAL Id: hal-00189140 https://hal.science/hal-00189140}

Submitted on 20 Nov 2007

HAL is a multi-disciplinary open access archive for the deposit and dissemination of scientific research documents, whether they are published or not. The documents may come from teaching and research institutions in France or abroad, or from public or private research centers.
L'archive ouverte pluridisciplinaire HAL, est destinée au dépôt et à la diffusion de documents scientifiques de niveau recherche, publiés ou non, émanant des établissements d'enseignement et de recherche français ou étrangers, des laboratoires publics ou privés. 


\title{
A FUZZY APPROACH FOR DISCRETE EVENT SYSTEMS RECOVERY
}

\author{
E. Minca ${ }^{(1)}$, D. Racoceanu ${ }^{(2)}$, Fl. Dragomir ${ }^{(1)}$, N. Zerhouni ${ }^{(4)}$ \\ (1) Computer Science Department \\ Valahia State University \\ 18-24, Unirii Ave. Targoviste, ROMANIA \\ E-mails: minca@valahia.ro, dragomir.florin@valahia.ro \\ (2) University of Besançon, France \\ E-mail: racoceanu@univ-fcomte.fr \\ (3) Ecole Nationale de mecanique et Microtechniques de Besançon, France \\ E-mail: zerhouni@ens2m.fr
}

\begin{abstract}
A fuzzy approach for modelling and analysing the recovery activities in discrete event systems is presented. Those essential components of the management of discrete event systems require special reasoning and methods to manage uncertain knowledge. For those purposes, we introduce a tool derived from the fuzzy Petri nets. This tool, inspired from the fault tree, generalizes the defects analysis by a temporal fuzzy approach. The correction requires a recovery which will be developed on a fuzzy rules basis. The recovery, modelled by a dedicated tool, preserves the fuzzy temporal aspect due to a real time information exchange mechanism provided by the monitoring system. Copyright $($ ) 2007 IFAC
\end{abstract}

Keywords: fuzzy expert system, detection, diagnosis, forecast, monitoring, recovery, fuzzy logic, fuzzy Petri nets

\section{FUZZY APPROACH IN MONITORING AND RECOVERY}

The complex analysis of discrete event systems requires specific methods and characteristic artificial intelligence reasoning. Between the existing modeling tools, Fuzzy Petri nets are one of the most appropriate for discrete event description using fuzzy knowledge (Cardoso and al., 1990). A complete state of the art of the various fuzzy Petri net (FPN) approaches was published by J. Cardoso, R. Valette and D. Dubois in (Cardoso and al., 1996; Valette and al., 1989). Important contributions in temporal marks evolution in a fuzzy approach are synthesized in (Looney, 1988).

To model the survey function, one uses an extension of fuzzy Petri nets (Minca and al., 2002a; 2002b) that integrates the moment of the defect appearance in the supervised system. The monitoring fuzzy Petri net (MFPN) (Minca and al., 2003c) is dedicated to the modeling of a fuzzy logic rule basis that follows from the logical expression of a fault tree (FT), a priori identified in the supervised system. The MFPN tool models the union or the intersection of the logical reasoning, respecting the specific concepts of the fuzzy logic (Bouchon-Meunier, 1994; Dubois and Prade, 1980; 1989). The analysis offers refined information at the level of each default/degradation, trough temporal synchronization signals.

MFPN highlights the characteristics of certain critical points which materialize the critical path in the strategy of the forecast function.

Unadapted to the modeling of the linear reasoning (Valette and Künzle 1994), the MFPN (Minca 2003a; 2003 b) is a tool with a limited generalization degree. It is not applied in the general modeling of the discrete event system temporal situations monitoring (Combacau, 1991; Grosdenier and Loonis 2004). In this sense, other fuzzy Petri nets tools model the fuzzy evolution of the marking (Cardoso and al., 1990).

The aim of this study is to propose a Petri net tool dedicated to the fuzzy modeling of the discrete event system recovery (RFPN). The tool is dedicated to the modeling of the fuzzy logic rules of a fuzzy expert system. It is then necessary to allow the modeling of 


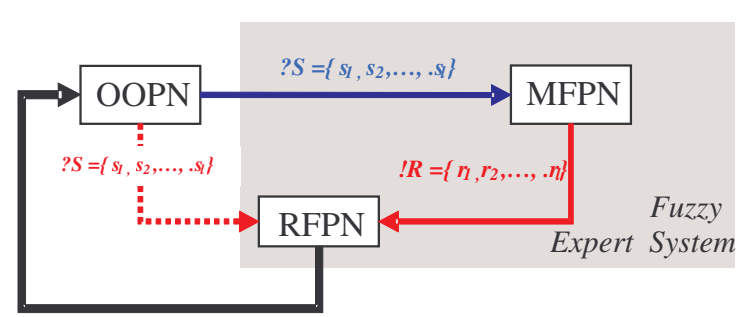

Fig. 1. Systemic representation of the detection, diagnostic and recovery functions

the logical fuzzy rules - conjunction and disjunction in the precedence or in the consequence of the rules, and especially the modeling of the inference of these rules.

To model the function of detection/diagnosis a dedicated tool is used: the MFPN. This tool receive the signals $? S=\left\{s_{1}, s_{2}, \ldots, . s_{l}\right\}$, emitted by the object oriented Petri net model (OOPN) (Combacau, 1991) which integrates the detection function and emits the signals $! \boldsymbol{R}=\{r l, r 2, \ldots, . r l\}$ in the moment of occurrence of the critical defects located on the places of the critical path of the MFPN. (Fig. 1).

The corresponding recovery model works in double interfacing with the monitoring (detection/diagnosis) system. The information is transferred by emission/reception signals, using the Petri nets with internal/external synchronizations (Racoceanu and al., 2002).

\section{FUZZY PETRI NETS FOR RECOVERY}

\subsection{The recovery problem}

The action of recovery claims a new tool able to integrate the fuzzy information sent in a synchronous way by the monitoring system, by considering it into a base of fuzzy logical rules. This detailed information can describe the critical state associated with the critical path in the MFPN model of the supervised system. The proposed tool - fuzzy Petri net for recovery (RFPN) - models a fuzzy expert system (FES). The fuzzy signals emitted by the detection system, activate certain places of the RPN network, defining the initial marking.

The variables modeled by the RFPN are the defaults located on the critical path - input variables and the correction actions of the system, command function, - output variables respectively. The proposed tool is able to modelize the fuzzyfication of these variables, and to extract the output variables which represent the correction function of the supervised system.

The logic rules base $\boldsymbol{R}$ is conceived according to the strategy adopted for an optimal recovery. The obtained RFPN model represents an alternative of fuzzy controller of the discrete event system. Certain places of the model generalize the modus ponnens operator by functions associated to places. The output of the system are either the system correction function or the correction of the supervised system in the standardized control, or the fuzzy signals from the recovery of the next decisional level subsystems of the following, which are integrated as input variables.

The recovery Petri net (RPN) is defined like a particular case of a general tool, represented by the category of the Fuzzy Petri net (FPN).

\subsection{Fuzzy Petri net definition}

A FPN is defined as being the n-uplet:

$F P N=\left\langle P^{+}, P^{-}, T, f^{+}, f^{-}, M_{0}, \dagger, \mathrm{I}, \mathrm{O}\right\rangle$

where:

$P^{+}$is the finite set of fuzzy places that associate to the tokens the functions :

$f^{+}=\left\{f^{+} \mid f:[0,1] \rightarrow[0,1]\right\}$;

$P^{-}$is the finite set of fuzzy places that associate to the tokens the functions $f^{-}=\left\{f^{-} \mid f^{-}:[0,1] \rightarrow[0,1]\right\} ;$

$T$ is the finite set of transitions;

$f^{+}$finite direct function set associated to the network places $\left\{P^{+}, P^{-}\right\}$. The $f^{+}$functions have as arguments the $\alpha$ fuzzy values of the tokens that are inputs for the places $P^{+}$. The output tokens of the $P^{+}$places have the fuzzy values $f^{+}(\alpha)$. The $f^{+}$

functions associated to the places $P^{-}$are bijective functions;

$f^{-}$finite reverse function set associated to the $\left\{P^{-}\right\}$ network places. The $f^{-}$functions have as arguments the $\alpha$ fuzzy values of the tokens that are inputs for the places $P^{-}$. The output tokens of the $P^{-}$places have the intermediary fuzzy values $f^{-}(\alpha)$ where $f^{-}$represents the reverse function $f^{-}=f^{-1}\left(f^{+}\right)$associated to $P^{-}$places;

$M_{0}: P \rightarrow[0,1]$ is the initial marking of the $\alpha$ fuzzy values associated to the tokens of the marked places;

$\uparrow$ represents the bijective function from the $f^{+}$set, to the network's places $\left\{P^{+}, P^{-}\right\}$ $\dagger:\left\{f^{+}, f^{-}\right\} \rightarrow\left\{P^{+}, P^{-}\right\}$;

$I: T \rightarrow\left\{P^{+}, P^{-}\right\}$and $O:\left\{P^{+}, P^{-}\right\} \rightarrow \mathrm{T}$ are the input and the output functions of the places.

Classically, transition $t_{j}$ firing - for a given marking $\mathrm{M}$, gives a new marking $\mathrm{M}^{\prime}$ such as:

$$
M^{\prime}=M-\operatorname{Pre}\left(., t_{j}\right)+\operatorname{Post}\left(., t_{j}\right)
$$

If the notation is:

-p the set of input transitions into the place $p$

p the set of output transitions from the place $\mathrm{p}$ and $m=\operatorname{card}(P) ; n=\operatorname{card}(T)$, then: 


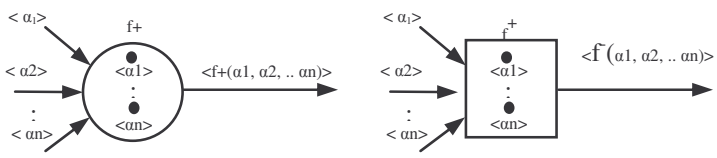

Fig. 2. Typologies of places for FPN

$$
\begin{aligned}
& U^{+}=\left[u_{i, j}\right], \quad u_{i, j}=\left\{\begin{array}{c}
w\left(t_{j}, p_{i}\right) \text { and } t_{j} \in \bullet p_{i} \\
0
\end{array}\right. \\
& U^{-}=\left[u_{i, j}\right], \\
& u_{i, j}=\left\{\begin{array}{c}
w\left(p_{i}, t_{j}\right) \cdot f\left(\alpha_{i}\right), f \in\left\{f^{+}, f^{-}\right\} \\
0
\end{array}\right. \\
& M_{0}=\left[\alpha_{i}\right]_{i=1, m}, \text { where } i=\overline{1, \operatorname{card}(P,) j}=\frac{\text { and } t_{j} \in p_{i} \bullet}{\operatorname{card}(T)} .
\end{aligned}
$$

For a sequence transition, materialized in the vector $V_{\sigma} \Rightarrow M^{\prime}=M+U \cdot V_{\sigma}$, with $U=U^{+}-U^{-}$.

The fuzzy value $\alpha$, associated to the token which remains in the place, will be modified by the associated function $f(\alpha)$, at the moment that it leaves the place. If the FPN network models some logical rules, it is well understood that certain functions $f^{+}$will be related to the fuzzy sets of the associated variables to places. In this case, as the places situated after the transition give the truth degree generated by the corresponding fuzzy logic rule.

\subsection{RFPN definition}

The RFPN network derived from the general model of the FPN.

$$
R P N=\left\langle P^{+}, P^{-}, T, f^{+}, f^{-}, M_{0}, \dagger, I, O, R, D, ? ! R\right\rangle
$$

with the following differences and characteristics:

$R$ is the fuzzy logical rule set;

$D=D^{x} \bigcup D^{y} \quad$ is the finite logical variable set. $D_{x}, D_{y}$ are logical variables associated with the logical description, by membership functions of logical variables $\{x, y\}$. These logical variables are in antecedence respectively in the consequence of the logical base of rules $R$;

$$
R=\bigcup_{w=1}^{r} R^{w}, R^{w}: D^{x} \rightarrow D^{y} \text { is the fuzzy logical rule }
$$

set. It is supposed that the set of rules $\mathrm{R}$ can be incomplete in respect of the exhaustive combination of the logical variables associated to the $\mathrm{D}^{\mathrm{x}}$ and $\mathrm{D}^{\mathrm{y}}$ variables;

$$
X^{k}=\left\{X_{1}, . . X_{k}\right\} \subset f^{+} \text {is the finite membership }
$$
functions set, defined on the universe of discourse $[0,1]$ of the variables $\left\{x_{1}, \ldots x_{k}\right\}$, associated to the logical variables belonging to $D_{x}$;

$k$ represents the number of variables that are in antecedence with the rules from $R$;
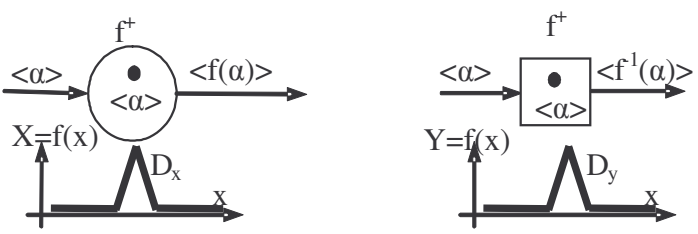

Fig. 3. Different $f^{+}$for RFPN

$Y^{q}=\left\{Y_{1} . . Y_{q}\right\} \subset f^{+}$is the finite membership functions set, defined on the universe of discourse $[0,1]$ of the variables $\left\{y_{1} . . y_{q}\right\}$, associated to the logical variables belonging to $D_{y}$;

$q$ represents the number of variables that are in consequence of the rules from $R$;

$? ! R$ represent fuzzy signals, sent by the detection/diagnosis model requiring for recovery services.

Each logical rule base $R$ models the fuzzy implications which describe the knowledge base of the expert system. Each implication respects the model IF-THEN and sets-up the logical dependence of the linguistic variables $\left\{\boldsymbol{D}^{x} \bigcup \boldsymbol{D}^{y}\right\}$ associated to the fuzzy sets $\left\{\boldsymbol{X}^{k}, \boldsymbol{Y}^{q}\right\}$. The composition of $K$ rules requires the aggregation mechanism.

There are two methods for the approximate reasoning: AI (the aggregation of rules followed by the inference) and IA (inference of each rule followed by aggregation).

Statement 1: All places of the network have associated $f^{+}$functions. For the places that are not a logical reason node, the function $f^{+}(x)=x$.

This function represents the neutral element in respect to the dynamics of the network marking.

Statement 2: The network places put in connection with the logical output variables of $R$, have associated the functions $f^{+}$that can provide the functions $\left\{f^{-}\right\}$.

Statement 3: At the level of the correspondent places as a result of each rule from $R$, the function $f^{+}$ represents the operator $\mathrm{T}$ - triangular norme corresponding to the inference mechanism

Statement 4: At the level of the correspondent places at the output of the expert system, the function $f^{+}$ represents the operator $\perp$ - triangular co-norme, corresponding to the aggregation mechanism

Statement 5: To determine the fuzzy variable associated with the rule base $R$, we applied the ZMA approach (Zadeh-Mamdani-Assilian) (BouchonMeunier, 1994). In this approach, a fuzzy rule is generally interpreted like a superposition of simultaneously true logical statements. 


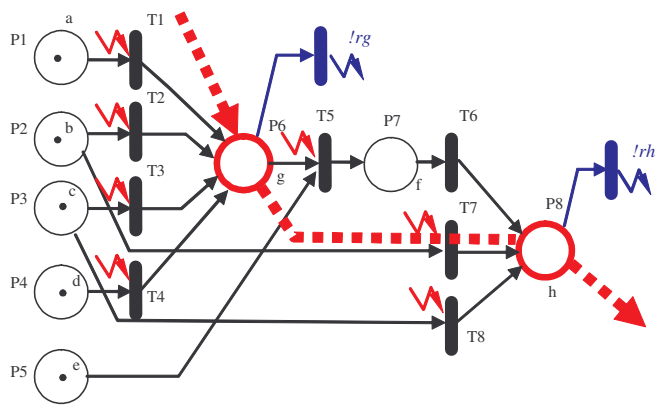

Fig. 4. F representation with MFPN

\section{APLICATION}

\subsection{Implementation of the detection and diagnosis} functions

We study the logical expression $\mathrm{F}$ of the defects propagation in a FT associated to a flexible production system (Proos, 2001):

$$
F=[(a+b+c+d) * e]+b+c .
$$

The mechanism of monitoring will be modeled using the MFPN tool (Minca and al, 2003c) (Fig. 4.).

\subsection{Implementation of the recovery functions using RFPN}

At the level of the $\mathrm{G}$ and $\mathrm{F}$ places it is possible to record critical defects signals, which claims the recovery of $! r_{g}, ! r_{h}$. The recovery signals are at the interface of MFPN with RFPN. A fuzzy rule base is defined to put the fuzzy control core in correspondence with the defects $g, f$ and the output commands $U_{1}, U_{2}$

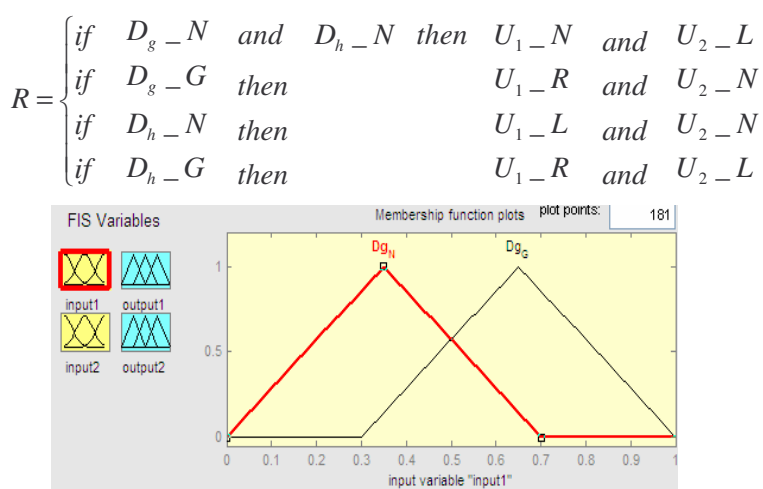

a)

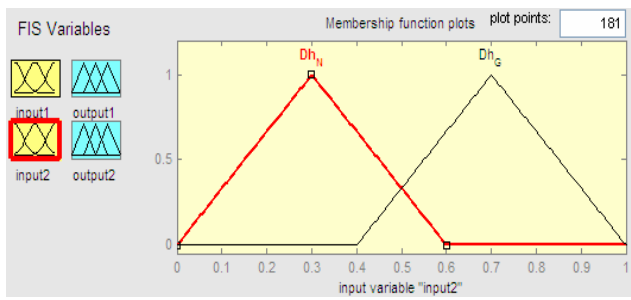

b)

Fig. 5. Membership functions for the input variables: a) $D_{g}$ and b) $D_{h}$

\subsection{Fuzzy rule base for the diagnosis-recovery}

By applying the proposed tool, we obtain the RFPN network (Fig. 8.). At the level of $D_{G}$ and $D_{h}$ places, we associate the membership functions of these variables to the fuzzy sets $\left\{D_{g}-N, D_{g}-G\right\}$ et $\left\{D_{h-N}, D_{h-G}\right\}$ (Fig. 5.).

RFPN is composed by eight layers, having precise associate $f^{+}$functions. At the input level (layer 1) one associates the membership functions for the places $\quad\left\{D_{g}-N, D_{g}-G, D_{h}-N, D_{h}-G\right\}$

(Fig. 8.).

At level of the corresponding places to layer 3, one associates bijective components for the membership functions of the variables $U_{1}, U_{2}$, to the fuzzy sets $\left\{U_{1-} L, U_{1-} N, U_{1-} R, U_{2}-L, U_{2-} N\right\}, \quad$ and $u_{i j}=U_{i j}^{-1}$ respectively, or linear dependence functions between the output components $\left\{U_{1-L}, U_{1-} N, U_{1-} R, U_{2}-L, U_{2-} N\right\} \quad$ (the Mamdani method) - and the input components $\left\{D_{g}, D_{h}\right\}$ respectively - (the case Sugeno), $u_{i j}=a U_{1}+b U_{2}+c$ (Fig. 7.):

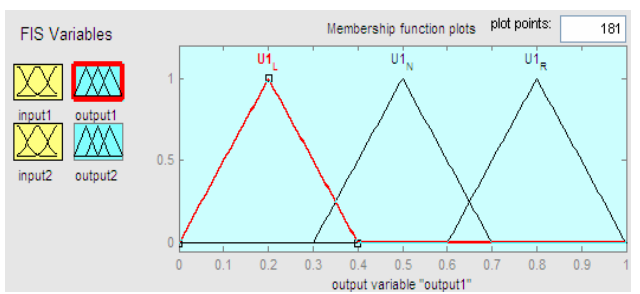

a)



b)

Fig. 6. Membership functions for the output variables: a) $\mathrm{U}_{1}$ and b) $\mathrm{U}_{2}$



Fig. 7. Input - Output fuzzy relation - Sugeno method 


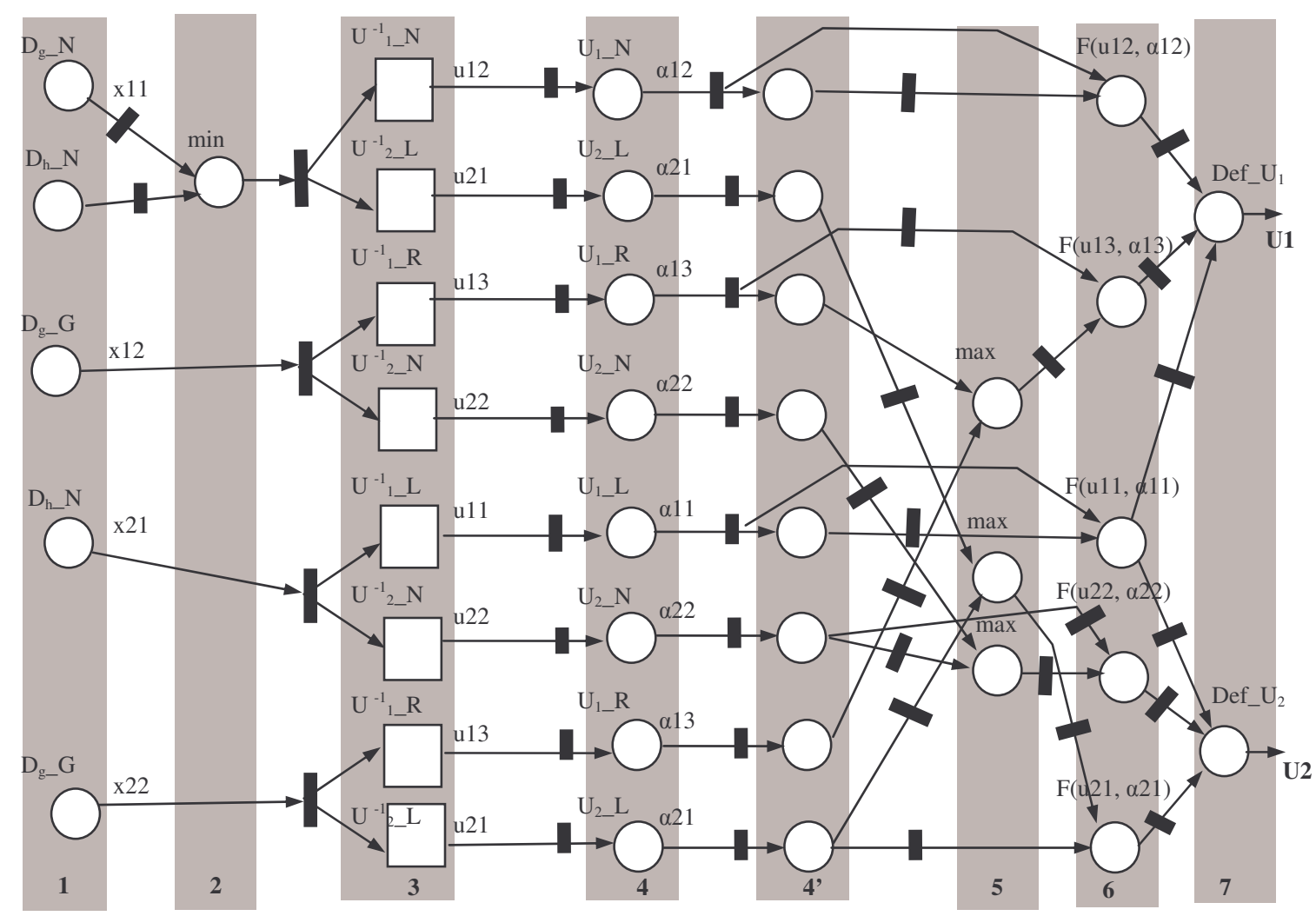

Fig. 8. The monitoring of system with RFPN

The places from the second layer materialize the inference mechanism of the rule 1 (from rule base $R$ ) and the places from the $5^{\text {th }}$ layer materialize the aggregation mechanism of the rules. Layer 4 materializes the values for the output variables.

For layer 4', the places have associated the $f^{+}(x)=x$ function which has the behavior of a neutral element in respect to the tokens migration between these places. The places located on this layer, materialize the output variables membership degree $U_{1}, U_{2}$ to the modelized sets $\left\{U_{1-} L, U_{1-} N, U_{1-} R, U_{2}-L, U_{2}-N\right\}$, for certain set of input data.

The places from the $6^{\text {th }}$ layer have associated the weight function between the output variable and the degree membership to logical variable: $U=u_{i j} \cdot \alpha_{i j}$ Finally, the two places located on the $7^{\text {th }}$ layer, materialize the defuzzyfication command recovery mechanism, while applying the function weighted average: $D e f_{-} U_{i}=\frac{\sum u_{i j} \cdot \alpha_{i}}{\sum \alpha_{i}}$

\section{CONCLUSIONS}

In this article, a fuzzy expert system modelling dedicated tool is proposed. This tool works in double interface with the model of the supervised system and with the corresponding model of the detection/diagnostic functions. The model exchange communication/synchronization signals.

For complex systems monitoring, our results permit to use a modular approach. The proposed tool forms an open monitoring system and gives also the possibility to integrate some others monitoring modules using other artificial intelligent techniques like neural networks.

In order to improve our fuzzy Petri net tool, possible future research will be oriented to an extension including the negation and other logical operations, by keeping our temporal specification.

\section{REFERENCES}

Bouchon-Meunier, B. (1994). La logique floue. Collection Que sais-je, 2702, Ed. Presses Universitaires de France, Paris.

Cardoso, J., R. Valette and D. Dubois (1990). Petri nets with uncertain markings, LNCS Advances in Petri nets, G. Rozenberg, Ed.Springer Verlang, 483, 64 - 78.

Cardoso J., R. Valette and D. Dubois (1996). Fuzzy Petri Nets : An Overview. $13^{\text {th }}$ Word Congress of IFAC, Vol I : Identification II, Discrete Event Systems, 443-448, San Francisco, CA, USA, 30 juin - 5 juillet.

Combacau, M. (1991). Commande et Surveillance des Systèmes a Évènements Discrets Complexes : Application aux Ateliers Flexibles. Thèse de doctorat, Université Paul Sabatier, Toulouse.

Dubois, D. and H. Prade (1980). Fuzzy Sets and Systems. Academic Press.

Dubois, D. and H. Prade (1989). Processing fuzzy temporal knowledge. IEEE Trans. On Syst. Man and Cyb., 4, 14.

Grosdenier, N. and Loonis P. (2004). Modélisation du suivi de situations par R'eseau de Petri. Le 
12eme Rencontres Francophones sur la Logique Flou et ses Applications, Nantes, France

Looney, C.G. (1988). Fuzzy Petri nets for rule-based Decision making. IEEE Trans. on Systems Man and Cybernetics, Jan-Feb, 18 (1), 178-183.

Minca, E., D. Racoceanu, N. Zerhouni and I. Brezeanu (2002). Fuzzy Based Petri Nets for the production Systems Diagnosis, Proceedings International Conference on Information Systems, Analysis and Synthesis, Electronics, Informatics and Control Systems - Invited Session, Orlando, Etats-Unis, XII.

Minca, E., D. Racoceanu, N. Zerhouni (2002). Monitoring Systems Modeling and Analysis Using Fuzzy Petri Nets. Studies in Informatics and Control Journal, Institut National de Recherche et de Développement en Informatique. 11 (4), Bucarest, Roumanie.

Minca, E., D. Racoceanu, N. Zerhouni and I. Brezeanu (2003a). Approche floue par la détection., Qualita2003, 5ème Congrès International Pluridisciplinaire Qualité et Sûreté de fonctionnement, Nancy.

Minca, E., D. Racoceanu, N. Zerhouni (2003b). Approche de détection par réseau de Petri flou. Pentom2003, Performance et Nouvelles Technologies en Maintenance., 26-28 mars. Valencienne.

Minca, E., D. Racoceanu, N. Zerhouni (2003c). Fuzzy logic Petri nets for monitoring systems modeling. IEEE International Conference on Robotics and Automation. Taiwan

Proos, S. (2001). Analyse des défaillances des systèmes industriels. Rapport de stage DEA Informatique, Automatique et Productique, Laboratoire d'Automatique de Besançon, France.

Racoceanu, D., N. Zerhouni, N. Addouche (2002). Modular modeling and analysis of a distributed production system with distant specialized maintenance. Proceedings of the 2002 IEEE International Conference on Robotics and Automation, 7 pages, 4046-4052, Washington, États-Unis.

Valette, R., J. Cardoso, D. Dubois (1989). Monitoring manufacturing System by means of Petri Nets with Imprecise Markings. IEEE International Symposium on Intelligent Control. Albany N.Y., USA.

Valette, R., I. A. Künzle (1994). Réseaux de Petri pour la détection et le diagnostic. Journées Nationales: Sûreté, Surveillance, Supervision. GdR Automatique, Paris, France. 